\title{
Zeta potential and surface charge of DPPC and DOPC liposomes in the presence of PLC enzyme
}

\author{
Emil Chibowski ${ }^{1} \cdot$ Aleksandra Szcześ $^{1}$
}

Received: 2 October 2015/Revised: 16 December 2015/Accepted: 16 January 2016/Published online: 1 February 2016

(c) The Author(s) 2016. This article is published with open access at Springerlink.com

\begin{abstract}
Zeta potential of liposomes is often measured in studies of their properties and/or applications. However, there are not many papers published in which zeta potential was determined during enzymatic reaction of a lipid. Therefore in this paper size, polydispersity index, and zeta potentials of 1,2-dipalmitoylsn-glycero-3-phosphatidylcholine (DPPC) and 1,2-dioleoyl-sn-glycero-3-phosphatidylcholine (DOPC) liposomes were investigated in $1 \mathrm{mM} \mathrm{NaCl}(\mathrm{pH}$ 6.2) and phosphate buffer ( $\mathrm{pH} 8.1)$ during 60 min of phospholipase $\mathrm{C}$ action at 20 and $37^{\circ} \mathrm{C}$. The hydrocarbon chains saturation differ these two phospholipids what appears in some differences in the zeta potential changes during the hydrolysis reaction run. The polydispersity index of the liposomes indicates that they are relatively stable and monodisperse, except for DPPC in phosphate buffer where up to $30 \%$ of the initial amount forms larger size moieties, possibly aggregates of the liposomes, enzyme and the hydrolysis products. However, in this buffer zeta potential of the liposomes practically does not change during PLC action. Also the changes of zeta potential of DOPC liposomes are minor, although their negative values are much smaller than those of DPPC at both temperatures. These small changes of the potential may be due to compression of the diffuse double layer by present phosphate buffer. However, distinct changes of the zeta potentials in the presence of PLC take place in $\mathrm{NaCl}$ solution. The observed changes can be explained by reorientation of the phospholipid polar heads and their
\end{abstract}

Aleksandra Szcześ

aszczes@umcs.lublin.pl

1 Department of Physical Chemistry - Interfacial Phenomena, Faculty of Chemistry, Maria Curie-Sklodowska University, 20-031 Lublin, Poland different density on DPPC and DOPC surface of the liposomes. Although it appeared that the zeta potential is not a very sensitive parameter for tracking the hydrolysis reaction in phosphate buffer, generally zeta potential enables the characterization of such reactions through determination of electrokinetic properties of liposomes as well as the polydispersity and size distribution of the liposomes do.

Keywords DPPC and DOPC liposomes - Phospholipase C. Zeta potential

\section{Introduction}

Liposomes are often used in studies of model biological membranes, phase transition and spacing, targeted drug delivery to specific areas of a human body, etc. They are uni- or multi-lamellar spherical structures whose diameter is between $15 \mathrm{~nm}$ and $>1 \mu \mathrm{m}$, and are classified as SUV (small unilamellar vesicles), LUV (large unilamellar vesicles) and MLV (multilamellar vesicles) (Akbarzadeh et al. 2013; Jones 1995). Cholesterol molecules happens to be incorporated into the phospholipid's bilayer thus causing increase separation between the choline head groups, reduces the hydrogen bonding strengths and electrostatic interaction. This makes the membrane more stable and lowers its permeability to water and other molecules (Ohvo-Rekilä et al. 2002; Róg et al. 2009). A special role plays calcium $\mathrm{Ca}^{+2}$ cations causing modulation of the insertion of proteins. Moreover, the cations adsorb not only by electrostatic interaction to the charged anionic phospholipids but also to zwitterionic lipid and polar heads (Raffo Iraolagoitia and Florencia Martini 2010). Among other applications, liposomes are used for gene transfection (Takeuchi et al. 1996) and targeted encapsulated drug 
delivery where they have to cross several cell membranes. Therefore lipophilic character, size, charge and hydrogen bonding are important parameters for characterization of the delivery efficiency. On the other hand, to increase liposomes stability their surface can be decorated with various polymers (Meland et al. 2014). Several review articles have been published (Akbarzadeh et al. 2013; Jones 1995; Barenholz 2001; Patil and Jadhav 2014) on preparation, characterization and applications of liposomes where above mentioned aspects are discussed.

In a model study phospholipid vesicles are also used to track the progress of enzymatic hydrolysis of the lipid. The enzymes causing the hydrolysis are phospholipases C (PLC) and A2 (PLA2). PLA 2 operate at native biological membranes (Mouritsen et al. 2006; Aloulou et al. 2006) and catalyze the hydrolysis of phospholipids at the $s n$-2 position thus producing free fatty acids and lysophospholipids. PLA 2 acts especially effectively at the domain boundaries, the regions with accumulated hydrolysis products, and the edges of holes in the bilayer (Wu et al. 2013; Wagner and Brezesinski 2008; Gudmand et al. 2010). The PLA2 activity is also enhanced on lipid vesicles of decreasing size, i.e. increasing curvature (Burack and Biltonen 1994). Phospholipase C (PLC) enzyme cleaves phospholipid near the phosphate group thus producing phosphocholine and diacylglycerol. PCL enzymes play an important role in signal transduction pathways (Bunney and Katan 2011; BamjiMirza and Yao 2015; Mo et al. 2009; Fisher and Mehendra 2009; Worthington Enzyme Manual).

In the studies of liposomes often their zeta potential is determined in various aspects, like stability of novel liposomes, encapsulation of drugs, decoration of the surface with a polymer, adsorption of ions, various pharmaceutical applications, etc. Adsorption of ions to the liposome surface causes change of zeta potential value or even its sign. In the case of hydrolysis reaction its ionic product, like fatty acid, can accumulate on the liposome surface and also influences its surface potential. Moreover, also adsorbed enzyme to the liposome may possibly affect its zeta potential. Remarkable value of zeta potential, say $>20 \mathrm{mV}$, should stabilize the liposomes and protect against their aggregation. Therefore, the zeta potential changes might be a valuable source of information shedding an additional light on liposome properties, including the hydrolysis reaction (Yamauchi et al. 1988; Zuidam et al. 1995; Zuidam and Crommelin 1995; Satoh 1995; Vaccaro et al. 1997; Liu et al. 2001; Ikonen et al. 2010). However, there are not many published papers on the zeta potential changes of liposomes occurring during the enzymatic hydrolysis reactions. Therefore it seemed us interesting investigation of the zeta potential changes accompanying the hydrolysis of DPPC and DOPC liposomes caused by PLC enzyme and calculation of their surface charge.

\section{Experimental}

\subsection{Materials}

1,2-Dipalmitoyl-sn-glycero-3-phosphocholine (DPPC, semisynthetic, $\geq 99 \%$ ), 1,2-Dioleoyl-sn-glycero-3-phosphocholine (DOPC, synthetic, $\geq 99 \%$ ) and PLC (Phospholipase $\mathrm{C}$ from Bacillus cereus, $32.77 \mathrm{U} / \mathrm{mg}$ solid, $405.07 \mathrm{U} / \mathrm{mg}$ protein) were supplied by Sigma and were used without further purification. However, the thin layer chromatography test has shown no detectable impurities in the phospholipids. This has confirmed similar test given by the manufacturer in the specification (Sigma Product Information). The enzyme is a monomeric protein $32 \mathrm{kDa}$, having two $\mathrm{Zn}^{2+}$ cations tightly bonded and optimal $\mathrm{pH}$ of its activity is 6.6-8.0. The lipids were dissolved in mixture of chloroform and methanol (p.a., POCH S.A., Poland). $\mathrm{NaCl}$ of concentration $10^{-3} \mathrm{M}$ and phosphate buffer solutions containing $\mathrm{Na}_{2} \mathrm{HPO}_{4}$ and $\mathrm{NaH}_{2} \mathrm{PO}_{4}$ (POCH S.A., Poland), was prepared using water from Milli-Q Plus system (Millipore, USA) with resistivity $18.2 \mathrm{M} \Omega \mathrm{cm}$. The $\mathrm{pH}$ of sodium chloride solution was natural and amounted 6.2 while that of the phosphate buffer solution was 8.1.

\subsection{Preparation of liposomes}

All the lipid vesicles were prepared by a thin film hydration method (Dual et al. 2012, Zaru et al. 2009). A thin lipid film was formed by dissolving the lipid (DPPC or DOPC) in chloroform/methanol solution $(2: 1, \mathrm{v} / \mathrm{v})$ in a round bottom flask and following removal of the solvent under vacuum condition (117 mbar, $24 \mathrm{~h}$ ) at room temperature, which ensured complete removal of the solvents. Then the dry lipid films were hydrated and extruded nine times through $0.1 \mu \mathrm{m}$ polycarbonate membranes using the Mini Extruder (Avanti Polar Lipids, Inc. USA) at $47{ }^{\circ} \mathrm{C}$ (DPPC liposomes) and $25{ }^{\circ} \mathrm{C}$ (DOPC liposomes). To remove any possible structural defects, the obtained liposomes were left for $1 \mathrm{~h}$ at the above temperatures, i.e. above their transition temperature, which is $41^{\circ} \mathrm{C}$ for DPPC (Zaru et al. 2009) and $-18{ }^{\circ} \mathrm{C}$ for DOPC (Lewis et al. 1988). Thus prepared liposomes were kept in a fridge in dark place. The total lipid concentration of the liposomes was always $0.625 \mathrm{mg} /$ $\mathrm{ml}$.

\subsection{Particle size, polydispersity and zeta potential determination}

The measurements were conducted in $1 \mathrm{mM} \mathrm{NaCl}(\mathrm{pH}$ 6.2) as a reference system and in phosphate buffer $\mathrm{Na}_{2}$ $\mathrm{HPO}_{4}+\mathrm{NaH}_{2} \mathrm{PO}_{4}$ at $\mathrm{pH} 8.1$ where to the liposomes $(0.625 \mathrm{mg} / \mathrm{ml})$ a portion of $25 \mu \mathrm{l}$ PLC enzyme $(4 \mathrm{mg} / \mathrm{ml})$ was added. The particle size and polydispersity index (PDI) 


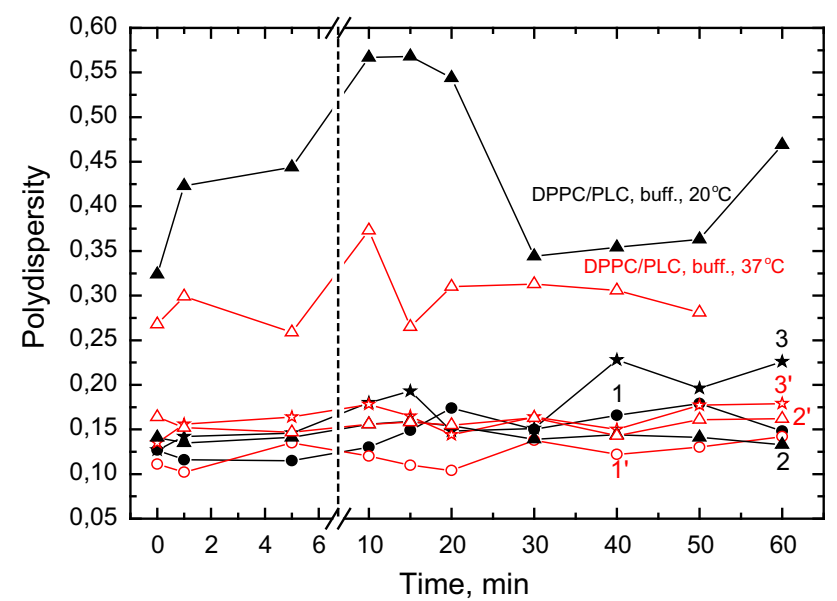

Fig. 1 Polydispersity index changes of DPPC and DOPC liposomes during $60 \mathrm{~min}$ of PLC enzyme action at 20 and $37{ }^{\circ} \mathrm{C}$. The superscript 'prime' at the numbers denote the changes at $37^{\circ} \mathrm{C}: 1,1^{\prime}-\mathrm{DOPC} /$ $\mathrm{NaCl}, 2,2^{\prime}-\mathrm{DPPC} / \mathrm{NaCl}, 3,3^{\prime}-\mathrm{DOPC} /$ phosphate buffer

of all the lipid vesicles were determined at $20{ }^{\circ} \mathrm{C}$ or at physiological temperature $37{ }^{\circ} \mathrm{C}$ with a help of Zetasizer Nano (Malvern Instruments Ltd., UK) equipped with a laser $(633 \mathrm{~nm})$ set at an angle of $173^{\circ}$. Dynamic light scattering is applied in the apparatus for determination of the particle sizes and their distribution which is calculated by the software of the apparatus. The size and distribution (percentage) of the particles (liposomes) have been evaluated from intensity of the dispersed light, which is the basic parameter in the apparatus software and it is then used for evaluation of the distribution by number and volume (for details see Manual Instruction of the ZetaSizer, Malvern Instruments Ltd., 2004).

If the PDI is less than 0.1 such dispersed systems are referred as monodisperse ones.

The size and zeta potential of the liposomes were first measured in the measuring cell of the apparatus without the enzyme presence, and then the enzyme was added to the sample of given liposomes, stirred by hand and the measuring cell was filled with the mixute and after $1 \mathrm{~min}$ first reading of the parameters was taken. The sample was kept in then apparatus for $60 \mathrm{~min}$ and the readings of the size, PDI and zeta potential were taken as shown in Figs. 1, 2 and 3 .

\section{Results and discussion}

\subsection{Polydispersity and size distribution of the liposomes}

Formation and/or accumulation of polar hydrolysis products in the membrane reflect in changes of hydrogen
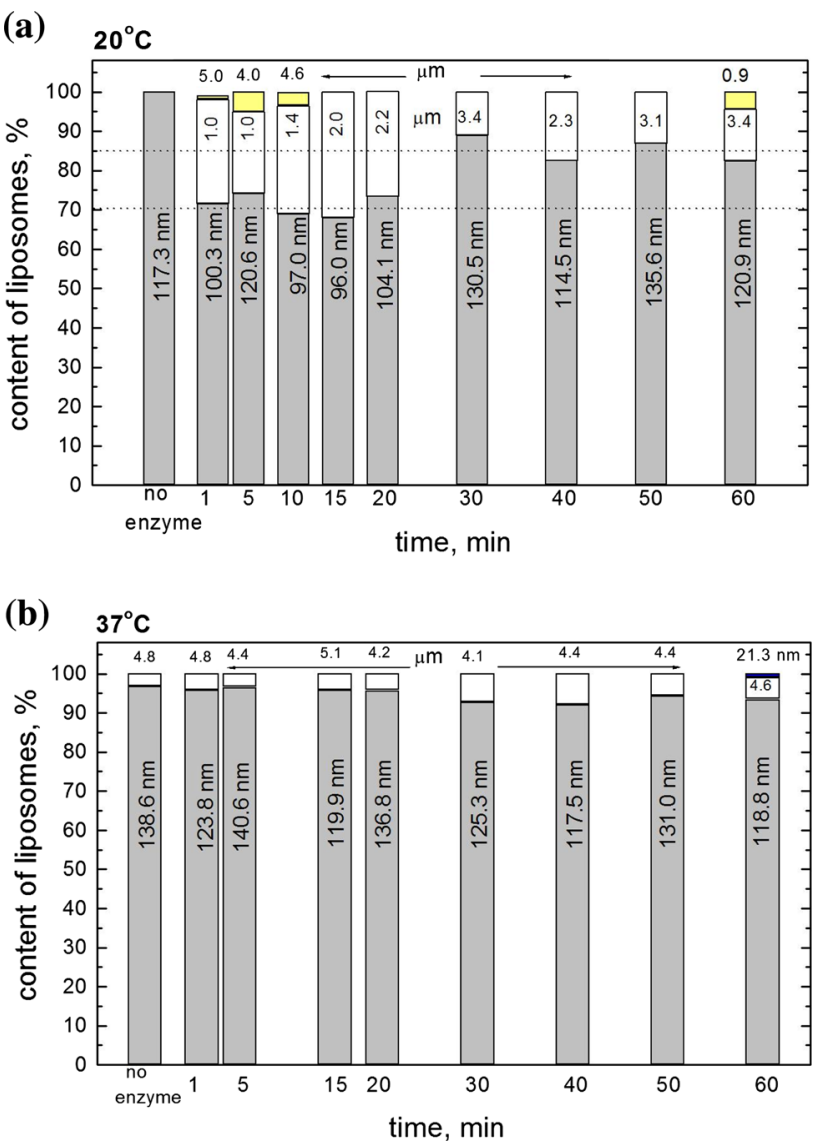

Fig. 2 Percentage content and size of the DPPC liposome fractions in phosphate buffer as a function of PLC enzyme action: $\mathbf{a}$ at $20^{\circ} \mathrm{C}, \mathbf{b}$ at $37^{\circ} \mathrm{C}$

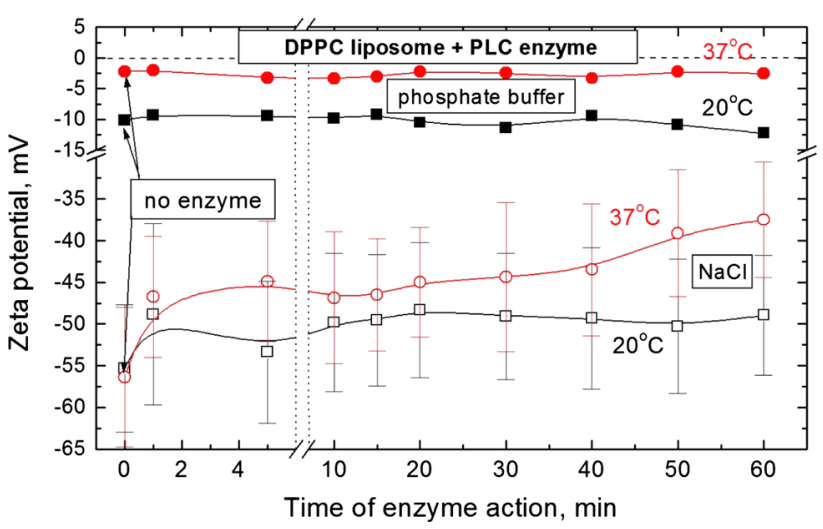

Fig. 3 Zeta potential of DPPC liposomes in the presence of PLC enzyme in $1 \mathrm{mM} \mathrm{NaCl}(\mathrm{pH} \mathrm{6.2)} \mathrm{and} \mathrm{phosphate} \mathrm{buffer} \mathrm{(pH} \mathrm{8.1)} \mathrm{at} 20$ and $37{ }^{\circ} \mathrm{C}$

bonding interactions. One may expect that also zeta potential of the phospholipid liposomes should be also sensitive to the enzyme action. Such changes might be a source of information shedding some additional light on the hydrolysis process (Zuidam et al. 1995; Zuidam and Crommelin 1995; Yamauchi et al. 1988; Vaccaro et al. 
1997). Using the same ZetaSizer apparatus, simultaneously with the zeta potential measurements, the size and polydispersity index of the liposomes during the enzyme action can be determined by dynamic light scattering. The initial size of DPPC and DOPC liposomes at $20{ }^{\circ} \mathrm{C}$ before the enzyme action was between $117 \mathrm{~nm}$ and $175 \mathrm{~nm}$ (see Table 1). As for the polydispersity index (PDI) of the DPPC and DOPC liposomes, for easier comparison, its changes at both temperatures, 20 and $37{ }^{\circ} \mathrm{C}$ during 60 min presence of PLC enzyme in $10^{-3} \mathrm{M} \mathrm{NaCl}$ or phosphate buffer are plotted in Fig. 1. These results show that except for two systems, polydispersity of the rest liposomes lies in the range of 0.15-0.20 at both temperatures and do not change much during $60 \mathrm{~min}$ of their contact with the PLC enzyme. Similar PDI index of DPPC liposomes, but of smaller size, was obtained by Hasanovic et al. (2010). Obviously, from the polydispersity index the concentration of the liposomes cannot be determined. Nevertheless, from the liposome size distribution measured simultaneously with PDI it was found that indeed, except for the above mentioned DPPC liposomes in phosphate buffer at $20^{\circ}$ and $37^{\circ} \mathrm{C}$, practically no changes of the size were observed. The changes of liposome size distributions in these two systems were remarkable and they are plotted in Fig. 2a, b. The results show greater changes at $20{ }^{\circ} \mathrm{C}$ than $37{ }^{\circ} \mathrm{C}$, especially during first $20 \mathrm{~min}$, where about $30 \%$ of the liposomes are of 1-2.2 $\mu \mathrm{m}$ size and some amount (ca. 1-3\%) of a large size (4-5 $\mu \mathrm{m})$ liposomes appears. Simultaneously during first $20 \mathrm{~min}$ the size of main fraction of the liposomes decreases by about $10-20 \mathrm{~nm}$ only. However, the mean size of this fraction during $60 \mathrm{~min}$ does not change much amounting $113 \pm 15 \mathrm{~nm}$, in comparison to $117 \mathrm{~nm}$ of their original size (Fig. 2a; Table 1). Very similar size DPPC and DOPC liposomes were obtained by Maharani et al. (2012) who used the same method of their preparation. The increased size of the liposome is probably due to their aggregation, possibly caused also by the enzyme adhesion and/or bridging mechanism by the hydrolysis products. At $37^{\circ} \mathrm{C}$ the original size of the liposomes is larger than at $20^{\circ} \mathrm{C}$, $139 \mathrm{~nm}$ and $117 \mathrm{~nm}$, respectively. However, at $37^{\circ} \mathrm{C}$ without the enzyme there is a fraction (ca. $3 \%$ ) of $4.8 \mu \mathrm{m}$ size (Fig. 2b), and similar size fraction (3-8\%) is present during $60 \mathrm{~min}$ of the hydrolysis. Again, mean size of the main fraction (92-97\%) changes only a little, $127 \pm 9 \mathrm{~nm}$. It is interesting that at the higher temperature the large liposomes $4.8 \mu \mathrm{m}$ appear from the very beginning, while at $20{ }^{\circ} \mathrm{C}$ larger fraction of the liposomes is of $1-3.4 \mu \mathrm{m}$, and only very small amount of 4-5 $\mu \mathrm{m}$ liposomes are seen during first $10 \mathrm{~min}$.

The hydrolysis kinetics of PC-lipids depends on temperature and $\mathrm{pH}$, and it is both acid and base catalyzed, but minimum of catalytic activity of PLC appears at pH 6-6.5

Table 1 Size $d$, Debye-Hückel parameter $\kappa, \kappa a$ value, zeta potential $\zeta$, and surface potential $\psi_{\mathrm{o}}$ of DPPC and DOPC liposomes in $1 \mathrm{mM}$ NaCl and phosphate buffer at 20 and $37^{\circ} \mathrm{C}$

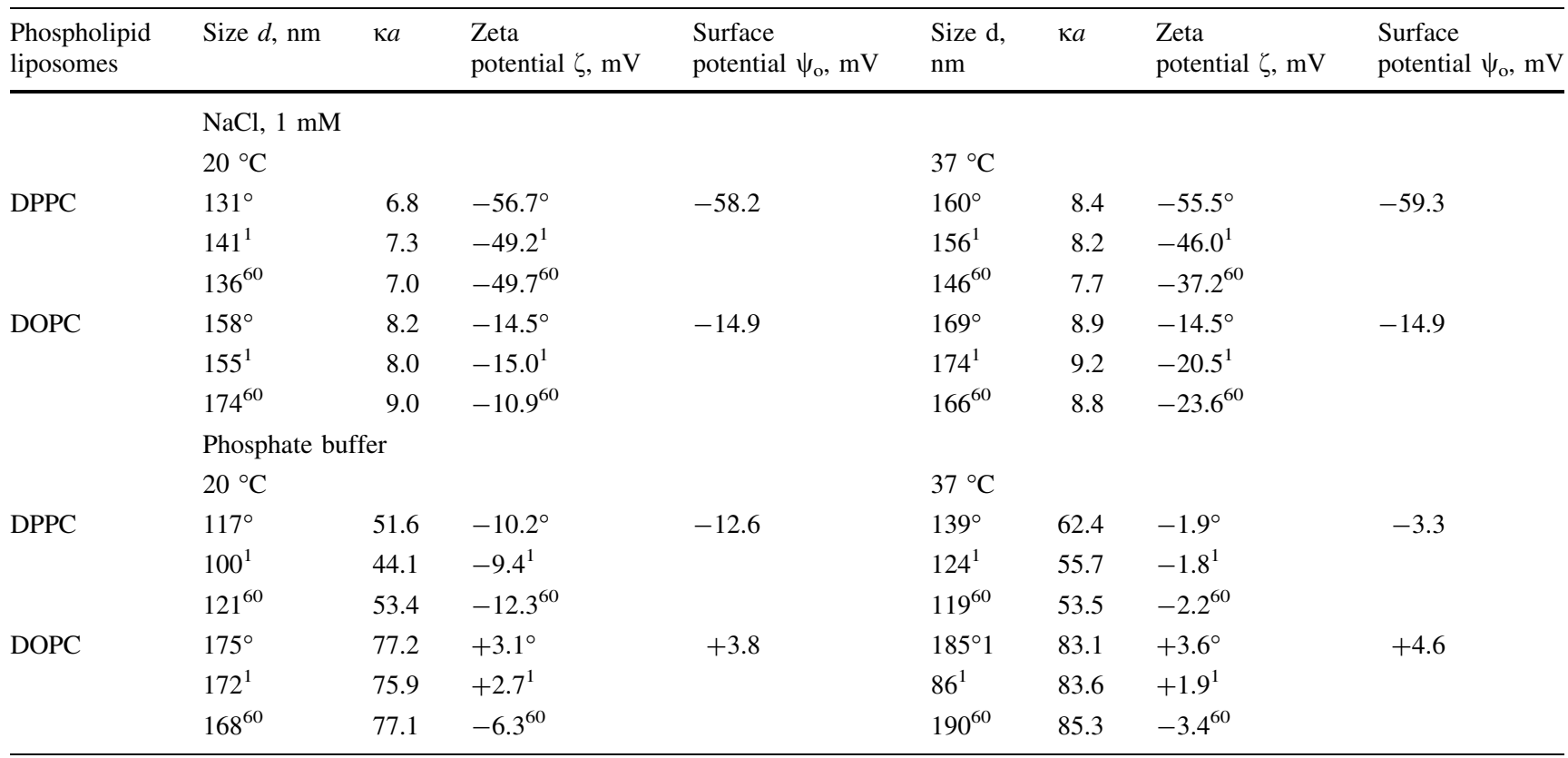

In the column 'zeta potential' the values denoted with the superscript 'o' are those measured without the enzyme presence, the second denoted with superscript ' 1 ' are the values obtained after $1 \mathrm{~min}$ of the enzyme action, and the denoted with superscript ' 60 ' are the values measured after 60 min of the enzyme action 
(Zuidam et al. 1995; Grit et al. 1993; Bergstrand 2003), which is the case in $\mathrm{NaCl}$ solutions. The results of Figs. 1 and 2 suggest that in the experiment conditions the hydrolysis reaction in phosphate buffer is more efficient for DPPC liposomes than DOPC ones. Then the question was whether the above results correspond somehow with the zeta potential changes of the liposomes. However, it appeared that in the buffer solution the zeta potential of the DPPC liposomes changes only a little, what is discussed below.

\subsection{Zeta potential of the liposomes}

The electrokinetic potential versus time of the enzymatic hydrolysis of DPPC and DOPC liposomes at the two temperatures $\left(20\right.$ and $37{ }^{\circ} \mathrm{C}$ ) are plotted in Figs. 3 and 4. The values were calculated from Henry's equation taking proper value of $\mathrm{f}(\kappa \mathrm{a})$ function calculated using $\kappa \mathrm{a}$ values $(\kappa$ is Debye-Hückel's parameter and $a$ is the liposome radius), which are given in Table 1 . It should be mentioned that in many published papers the zeta potential of the liposomes was calculated from Helmholtz-Smoluchowski equation (e.g. Raffo Iraolagoitia and Florencia Martini 2010; Satoh 1995) which in many cases is not appropriate one for the nanometer size moieties (liposomes). As can be seen from Fig. 4, except for the initial small positive zeta potential $(+3.5 \mathrm{mV})$ of DOPC liposomes in phosphate buffer (first $5 \mathrm{~min}$ ), in the rest cases the potentials are negative. Moreover, the zeta potential of DPPC liposomes in phosphate buffer and in the presence of PLC practically does not change during $60 \mathrm{~min}$ at both temperatures 20 and $37{ }^{\circ} \mathrm{C}$, ca. -1 and $-2 \mathrm{mV}$, respectively (Fig. 3; Table 1), which contrasts with PDI changes (Fig. 1) and size distribution (Fig. 2) of these liposomes. In the case of DOPC liposomes in the buffer small changes of the zeta potential during $60 \mathrm{~min}$ are seen, from +3.5 to $-7.5 \mathrm{mV}$ at $20^{\circ} \mathrm{C}$,

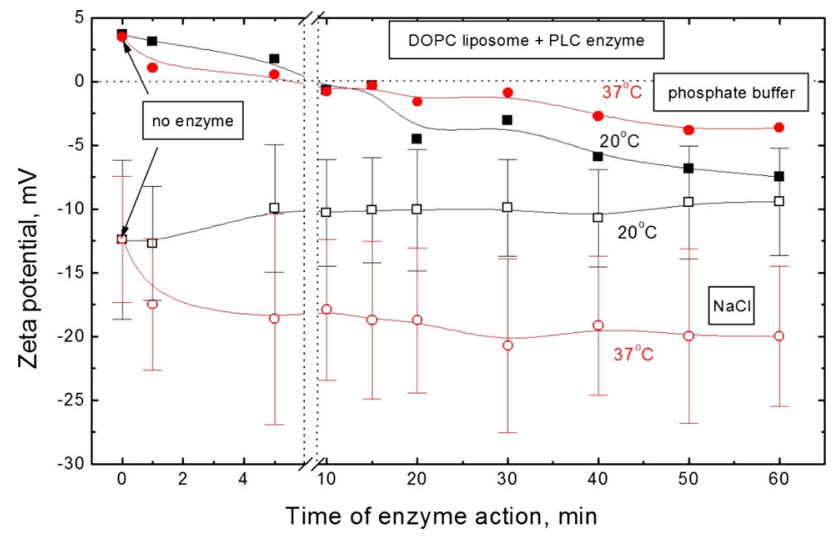

Fig. 4 Zeta potential of DOPC liposomes in the presence of PLC enzyme in $1 \mathrm{mM} \mathrm{NaCl}(\mathrm{pH} \mathrm{6.2)}$ and phosphate buffer (pH 8.1) at 20 and $37^{\circ} \mathrm{C}$ and from $+3.5 \mathrm{mV}$ to $-3 \mathrm{mV}$ at $37{ }^{\circ} \mathrm{C}$, (Fig. 4; Table 1). Relatively big values of the zeta potential are observed for DPPC liposomes in $\mathrm{NaCl} / \mathrm{PLC}$ solution at both temperatures, which initially are $-56.7 \mathrm{mV}$ (at $20{ }^{\circ} \mathrm{C}$ ) and $-59.3 \mathrm{mV}$ (at $37^{\circ} \mathrm{C}$ ), and after $60 \mathrm{~min}$ of the enzyme presence they decrease to -49.7 and $-37.2 \mathrm{mV}$, respectively (Fig. 3; Table 1). The absolute zeta potentials of DPPC liposomes in the presence of PLC are higher at 20 than $37{ }^{\circ} \mathrm{C}$ and they decrease during the reaction time (Fig. 3). The situation is reversed in the case of DOPC liposomes (Fig. 4) but the absolute zeta potentials of these liposomes are much smaller. Such different behavior one can consider to result from different orientation of the zwitterion heads of these two phospholipids. In Figs. 3 and 4 there are also shown standard deviations of the zeta potential in $\mathrm{NaCl}$ solution for DPPC and DOPC liposomes. They are in the range of up to $10 \mathrm{mV}$ and point that the zeta potential of these liposomes fluctuates, or the net charge of the particular liposome vesicles differs. However, from the protocols of zeta potential measurements shown in Fig. 5 it results that quality of the measurements was good and only one peak of the zeta potential appeared with one exception for DPPC original liposomes (no enzyme) at $37{ }^{\circ} \mathrm{C}$, where 3 peaks were detected: $-41.0 \mathrm{mV}(62.5 \%),-53.3 \mathrm{mV}$ (36.9\%), and $-13.4 \mathrm{mV}(0.6 \%)$. Note, these zeta potentials were calculated by the apparatus software. In fact this low-zeta-potential fraction is negligible and the apparent zeta potential results from the two significant fractions of the liposomes possessing a bit different charge. The explanation of these three different values of the zeta potential at $37{ }^{\circ} \mathrm{C}$ could be based on the model proposed by Makino et al.'s (1991) that the polar heads of the phospholipid may orient in different way at the surface, which results in negative, positive or even zero zeta potential. Although at $37{ }^{\circ} \mathrm{C}$ DPPC is still below its transition temperature $\left(41^{\circ} \mathrm{C}\right)$, nevertheless the flexibility of the molecules on the liposome surface at $37{ }^{\circ} \mathrm{C}$ must be larger than at $20^{\circ} \mathrm{C}$.

One may also dispute the relatively big zeta potential values of DPPC liposomes in $1 \mathrm{mM} \mathrm{NaCl}$ solution in comparison to some met in the literature (Raffo Iraolagoitia and Florencia Martini 2010; Satoh 1995; Hasanovic et al. 2010; Maharani et al. 2012; Makino et al.'s 1991). As was mentioned above, partially it might be due to using the Helmholtz -Smoluchowski equation instead of Henry's equation (Hunter 1981) or numerical calculation (O'Brien and White 1978) to calculate the zeta potentials from the electrophoretic mobilities. However, similar values of zeta potential of DPPC and DOPC liposomes to those obtained by us have been obtained by del C. Luzardo et al. (1998). They obtained DPPC and DOPC multilameral liposomes by dispersing the phospholipid films in $1 \mathrm{mM} \mathrm{KCl}$. The samples were purchased from Avanti Polar Lipids and used 
(a)

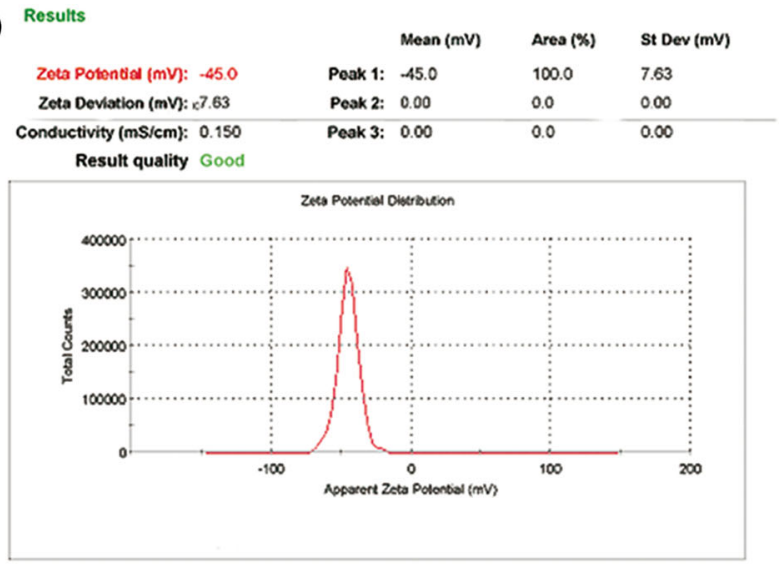

(b)

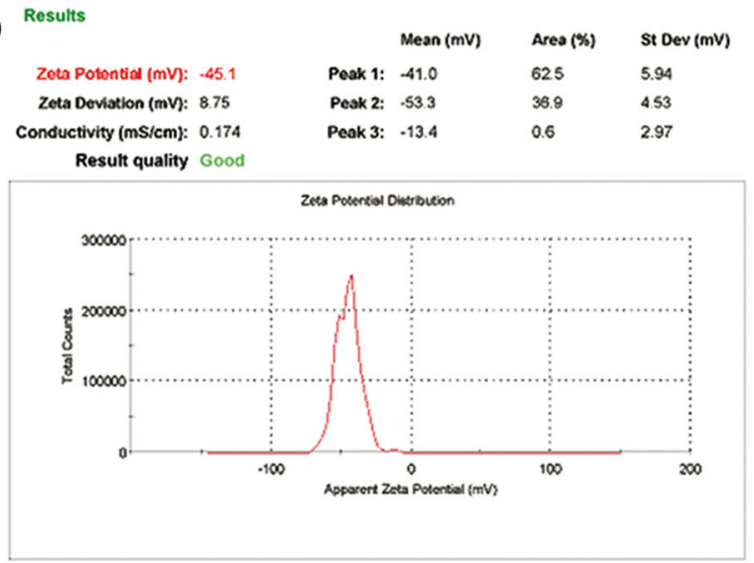

Fig. 5 Protocols of zeta potential measurements of DPPC liposomes in $1 \mathrm{mM} \mathrm{NaCl}$ : at $20^{\circ} \mathrm{C}$. a-no enzyme, a $\mathrm{a}^{\prime}$-after $60 \mathrm{~min}$ PLC enzyme action; at $37^{\circ} \mathrm{C}$, b-no enzyme, $\mathbf{b}^{\prime}$-after 60 min PLC

as received but their purity was checked by thin-layer chromatography. They calculated the zeta potential values from electrophoretic mobility results and HelmholtzSmoluchowski equation. The calculated zeta potentials were $c a$. 35-52 mV (Figs. 3, 4; del C. Luzardo et al. 1998), which actually would be even higher if calculated from Henry's equation (Hunter, 1981). However, size of the liposomes is not given in the paper and therefore Henry's equation cannot be applied to recalculate and verify those zeta potential values calculated from Helmholtz-Smoluchowski equation.

In the systems studied, except for the one case mentioned above, the zeta potential is negative. The sign and magnitude of zeta potential is determined by net charge accumulated on the liposome surface. The phospholipid DPPC and DOPC molecules are zwitterionic and according to Makino et al. (1991) their polar heads can reorient (a')

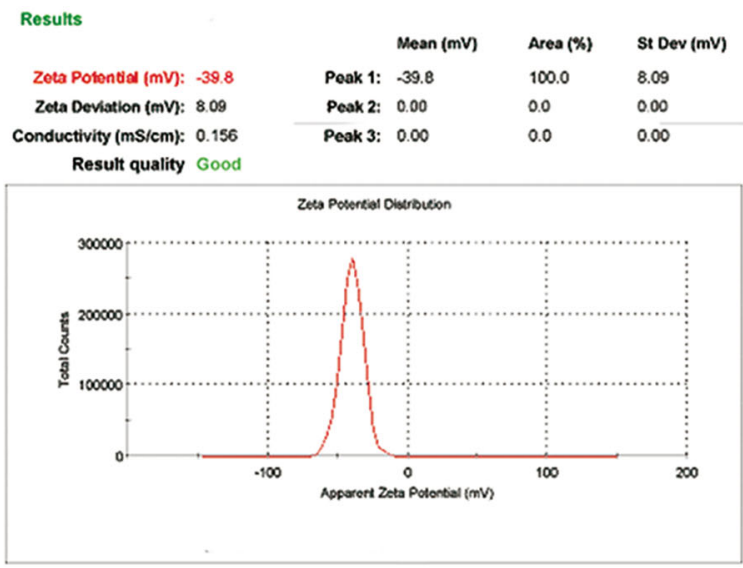

(b')
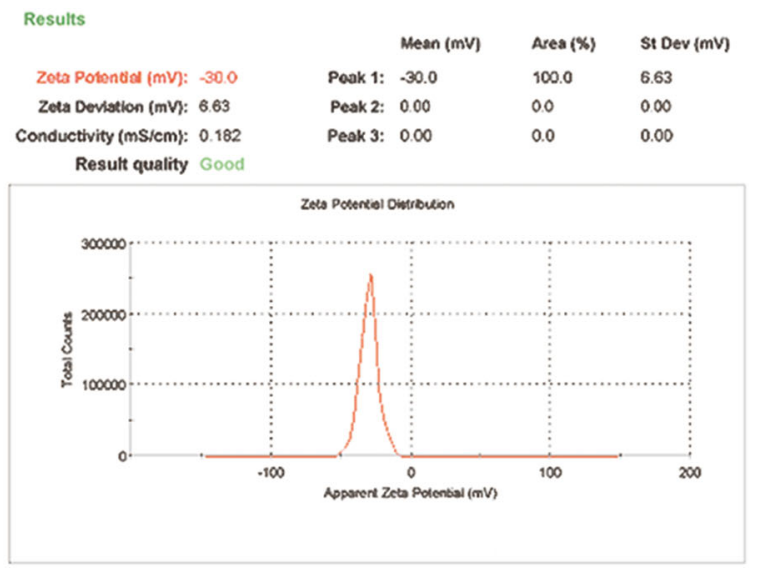

enzyme action. Note the zeta potential are calculated from Helmholtz-Smoluchowski equation by the ZetaMeter software

depending on the ionic strength. It reflects in the zeta potential whose changes with the ionic strength can be interpreted via changes of the polar heads orientation, as well compression of the diffuse part of electric double layer. At a low ionic strength the choline groups are located below the phosphate group (negative zeta potential), whereas at a high ionic strength the situation is reversed. According to these authors the zero zeta potential occurs if DPPC polar heads are oriented parallel to the liposome surface. In $10^{-3} \mathrm{M} \mathrm{NaCl}$ solution (the ionic strength $\mathrm{I}=0.001 \mathrm{~mol} / \mathrm{dm}^{3}$ ) the concentration of the ions is low; $1 \mathrm{mM}$ of $\mathrm{Na}^{+,} 1 \mathrm{mM}$ of $\mathrm{Cl}^{-}$, and negligible amounts of $\mathrm{H}^{+}$ and $\mathrm{OH}^{-}$ions ( $\mathrm{pH}$ 6.2). In the phosphate buffer (the ionic strength $\mathrm{I}=0.0333 \mathrm{~mol} / \mathrm{dm}^{3}$ ) the salts concentration is; $0.095 \mathrm{M} \mathrm{Na}_{2} \mathrm{HPO}_{4}$ and $0.005 \mathrm{M} \mathrm{NaH}_{2} \mathrm{PO}_{4}$. Hence the ions concentration is; $94.7 \mathrm{mM} \mathrm{HPO}_{4}{ }^{2-}, 5.3 \mathrm{mM} \mathrm{H}_{2} \mathrm{PO}_{4}{ }^{-}$, $194.7 \mathrm{mM} \mathrm{Na}^{+}$, and some negligible concentration of $\mathrm{H}^{+}$ 
and $\mathrm{OH}^{-}$ions $(\mathrm{pH}$ 8.1). During the hydrolysis reaction by PLC the polar products are: (1) diacylglicerol (DAG) and (2) phosphocholine (PC).

1)<smiles>[R]C(=O)OCC(CO)OC([R])=O</smiles>

734 , i.e. it is 31 times smaller than that of the enzyme. However, the outer shell of the original DPPC liposome in $1 \mathrm{mM} \mathrm{NaCl}(\mathrm{pH} 6.2)$ consists of $82.9 \times 10^{3}$ molecules

2)<smiles>C[N+](C)(C)CCOP(=O)([O-])O</smiles>

As discussed above, the largest negative zeta potential is found for DPPC liposomes in $\mathrm{NaCl}$ solution without the enzyme presence, $55-56 \mathrm{mV}$ at both temperatures. The larger zeta potentials in $\mathrm{NaCl}$ solution than those in the phosphate buffer partially may result from 33 times higher ionic strength in the buffer than in $\mathrm{NaCl}$ solutions, which causes compression of the diffuse double layer. The differences observed for DPPC and DOPC (Figs. 3, 4) are probably caused by the fact that the packing of DOPC molecules in the layer is looser $\left(0.67-0.69 \mathrm{~nm}^{2}\right)$ than in DPPC (0.46-0.49 $\mathrm{nm}^{2}$ ) layer (Vaknin et al. 1991), resulting from two unsaturated bonds present in DOPC hydrocarbon chains. The negative zeta potential of DPPC liposomes in low concentrated $1 \mathrm{mM} \mathrm{NaCl}$ may results from the exposed phosphate negatively charged groups outward (Makino et al. 1991), while adsorption of $\mathrm{Cl}^{-}$ions rather does not takes place there (Ikonen et al. 2010). Small zeta potential values in the phosphate buffer suggest that phosphate ions do not adsorb in large amounts to the liposome headgroups, what would compete with the diffuse layer compression caused by the high ionic strength. As discussed above, the larger negative values of zeta potential of DPPC than DOPC liposomes can be explained by a larger number of phosphocholine groups on a unit surface of DPPC liposome. The small changes, or practically no change, of the zeta potential during the PLC hydrolysis reaction can be explained by the fact that the hydrolysis products; diacylacohol and zwitterionic phosphocholine are not ionic molecules that would increase the negative zeta potential by accumulating on the liposome.

One can also consider whether the enzyme can contribute to the measured electrophoretic mobility and calculated zeta potential (Salgin et al. 2012; Yamauchi et al. 1999). The molecular weight of used enzyme PLC from Bacillus cereus amounts $23 \mathrm{kDa}$ and contains 2 tightly bound $\mathrm{Zn}^{2+}$ cations whose optimal $\mathrm{pH}$ range is 6.6-8.0 (Sigma Product Information). The detailed study of Bjorklid and Little (1980) showed that the isoelectric point of the native sample containing two zinc cations was $6.88 \pm 0.05$. The molecular weight of DPPC molecule is $(\mathrm{d}=131 \mathrm{~nm})$, which is equivalent to $60.8 \mathrm{kD}$ and about the same amount is closed in the inner shell. Thus the size of the liposome is at least 6 times larger than PLC enzyme and at $\mathrm{pH} 6.2$ the enzyme is slightly positively charged which may results in a weak electrostatic interaction with negatively charged DPPC liposome. However, from the liposome size distribution (Fig. 2a) and zeta potential values (Fig. 3) it can be concluded that in phosphate buffer solution at $\mathrm{pH} 8.1$ both the liposome and enzyme possess small negative zeta potentials and the electrostatic interaction is not the driving force for the enzyme adsorption but rather hydrogen bonding and London dispersion forces. The big moieties detected by the dynamic light scattering (Fig. 2) may consisting of the DPPC molecules, enzyme and the hydrolysis product, which is $10-30 \%$ fraction of the total amount and 70-90\% are the liposomes of their original size and charge. Thus, it may be concluded that the PLC enzyme does not contribute to the measured electrophoretic mobility and calculated zeta potential.

\section{Profile of electric potential across the liposome bilayer}

It seemed us interesting to depict contribution of the zeta potential to the potential profile across phospholipid bilayer. For this purpose available literature experimental results and molecular modeling (CHARMM36 force field model) were used (Satoh 1995, Liu et al. 2001; Warshawiak et al. 2011; Clarke 2001) and the constructed scheme of the potential profile across DOPC bilayer is drawn in Fig. 6. Across about 5-nm-thick bilayer the total potential drop $\Delta \Psi$ is evaluated to be $c a .70 \mathrm{mV}$ and the electrokinetic slip plane is located about $0.24 \mathrm{~nm}$ from the liposome surface. This $\Delta \Psi$ potential drop is due to the difference in ions concentrations in the bulk liquids on both sides of membrane. However, the changes of potential inside the bilayer amount several hundred millivolts. Water dipoles are incorporated between the polar heads (up to 4-6 dipoles per one polar head (Vaknin et al. 1991; Milhaud 
Fig. 6 A scheme of the electrical potential profile across the DOPC bilayer based on the data from ref. (Satoh 1995; Liu et al. 2001; Warshawiak et al. 2011; Clarke 2001)

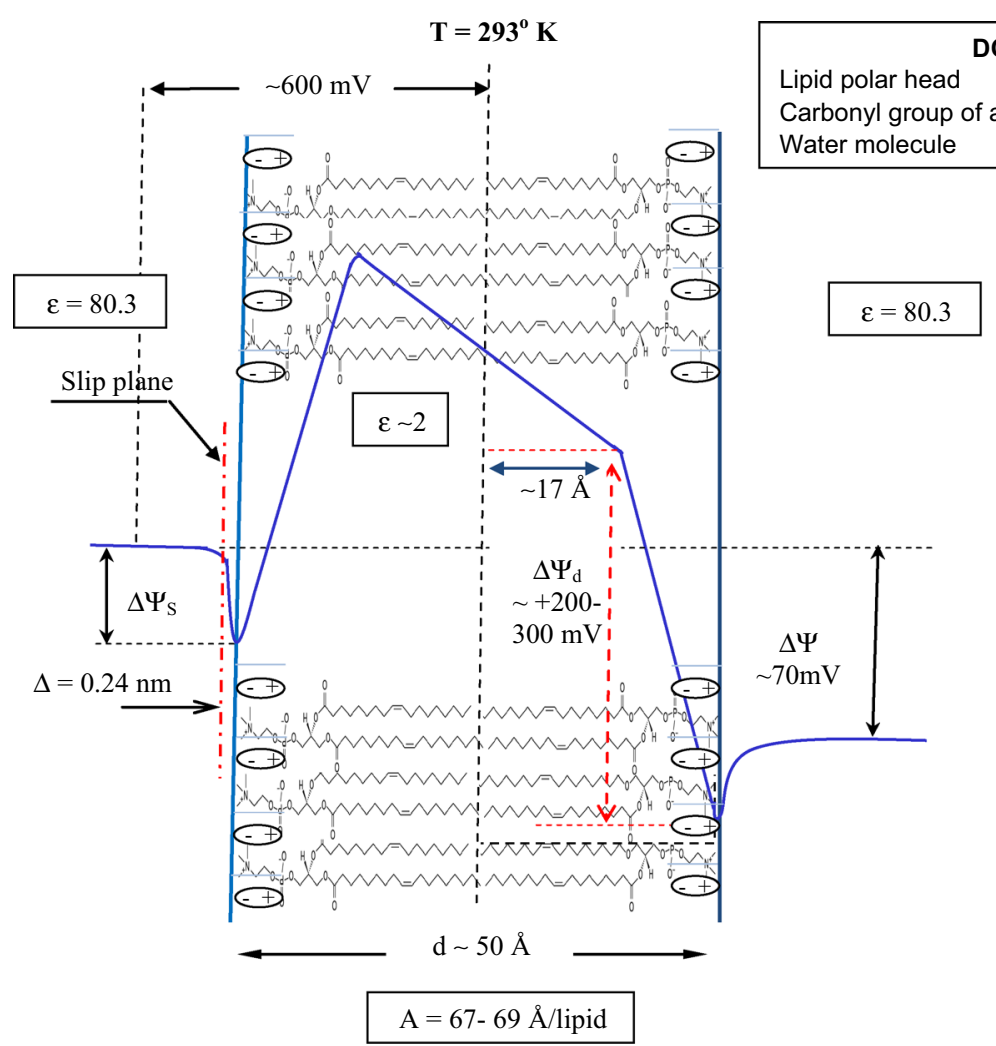

DOPC

$\mu=18-25 D$

$\mu=2.5 D$ $\mu=1.8 \mathrm{D}$
2004) and the maximum potential due to water and phospholipid dipoles alignment appears about $1.7 \mathrm{~nm}$ from the center of the bilayer (i.e. close to the position of oxygen atoms of ester) and it may amount $+200-300 \mathrm{mV}$ (differing for DOPC and DPPC), while that from the center of the bilayer to the bulk water might be as big as $+600 \mathrm{mV}$. The contribution to the dipole potential jump from phospholipid head groups $(\mu=18-25 \mathrm{D})$ is negative while that from the water dipoles $(\mu=1.8 \mathrm{D})$ is positive. The zeta potential $\zeta$ is the potential in the slip plane relative to the reference zero potential placed in the bulk solution and it is only a fraction of the potential $\psi_{\mathrm{o}}$ located on the surface of liposome arising from the charged headgroups as well the ion adsorption on the surface. The molecular interpretation of zeta potential origin have been lately discussed by Lyklema (2010, 2011), who concluded that "structuring water which adjacent to solid surfaces is the universal physical origin for the ubiquitous occurrence of stagnancy", and "only a small part of the countercharge is electrokinetically active". Fluid between the surface and the slip plane is considered to be stagnant and appears both at hydrophilic and hydrophobic surfaces. Moreover, the stagnant layer is very similar at positively and negatively charged surfaces. $\mathrm{He}$ also concluded that the origin of stagnancy is not caused by the interaction between the first water layer and the surface and the electrokinetic charge can maximally amount only a few $\mu \mathrm{C} \mathrm{cm}{ }^{-2}$. Although the dipole potential cannot be directly measured experimentally but via some indirect experiments it can be evaluated (Clarke 2001; Wang 2012), on the other hand neither DPPC nor DOPC molecules possess net charge in a broad range of $\mathrm{pH}$, and hence it was postulated that the surface potential may arise from oriented head groups (dipoles) (Makino et al. 1991) of the lipid molecules, among others reasons, because even in $1.0 \mathrm{M} \mathrm{KCl}$ the zeta potential was measured where no diffuse ionic double layer should be present, and any changes in the bilayer structure have to change the dipole potential (Warshawiak et al. 2011; Haldky and Haydon 1973; Gross et al. 1994). Moreover, changes in the ionic strength (from $1 \mu \mathrm{M}$ to $1 \mathrm{M} \mathrm{KCl}$ ) do not cause any significant changes in the dipole potential, which of course causes changes in the surface potential (Gross et al. 1994).

Similar model of the potential profile across the DPPC bilayer can be also drawn. Obviously, because of different packing of its bilayer than that of DOPC the electrostatic potential vs. distance run in a different way. For example, the total dipole potential originating from lipid and water dipoles from the bilayer center to water bulk phase was evaluated for $-500 \mathrm{mV}$ (Becker et al. 2001). Depending on the bilayer packing the potential may lay between -200 and $575 \mathrm{mV}$ (Muddana et al. 2011, Patra et al. 2003). Because the potential profile across the lipid bilayer was not principal issue of our investigation it will be not further discussed. 


\section{Surface potential and surface charge of the liposome}

Finally, also it seemed interesting to calculate the surface potential $\Psi_{\mathrm{o}}$ and then the surface charge of the liposomes using the measured zeta potential values. The surface potential was calculated from Eq. 1 (Bard and Faulkner 2001).

$\frac{\tanh \left(\frac{z_{i} F}{4 R T} \zeta\right)}{\tanh \left(\frac{z_{i} F}{4 R T} \Psi_{o}\right)}=\exp (-\kappa x)$

The slip plane location was assumed to be at $\mathrm{x}=0.24 \mathrm{~nm}$ from the liposome surface independently of the ionic concentration as postulated by Satoh (1995). In Table 1 are listed, the Debye-Hückel parameter $\kappa$ and $\kappa a$ product, the zeta potential $\zeta$ calculated from Henry's equation, and the surface potential $\Psi_{\mathrm{o}}$ calculated from Eq. 1. The zeta potentials were calculated for; enzyme free solution, after $1 \mathrm{~min}$, and after 60 min contact with PLC at both temperatures and the actual size of the principal fraction of the liposomes was taken for the calculation. The largest negative zeta potential was obtained for the DPPC liposomes in $\mathrm{NaCl}$ solution (Figs. 3, 4; Table 1). As can be seen in Table 1 thus calculated surface potentials $\Psi_{\mathrm{o}}$ do not differ much from the zeta potentials $\zeta$. Then the surface charge was calculated only for DPPC liposomes in $1 \mathrm{mM}$ $\mathrm{NaCl}$, whose negative surface potential $\Psi_{\mathrm{o}}$ is one of the biggest $-58.2 \mathrm{mV}$, assuming both planar (which for most systems here is not justified) and spherical model of the electrical double layer, Eqs. (2) and (3), respectively (Lyklema 2011; Oshima and Furosawa 1998).

$\sigma_{o}=\left(8 R T c \varepsilon_{r} \varepsilon_{o}\right)^{1 / 2} \sinh \left(\frac{z_{i} F}{2 R T} \Psi_{o}\right)$

$\sigma_{o}=\left(8 n \varepsilon \varepsilon_{o} k T\right)^{1 / 2}\left[\sinh \left(\frac{e \Psi_{0}}{2 k T}\right)+\frac{2}{\kappa a} \tanh \left(\frac{e \Psi_{o}}{4 k T}\right)\right]$

where $\varepsilon_{\mathrm{o}}$ is the permittivity of free space, $\varepsilon$ is the relative static permittivity, $\mathrm{c}$ is the bulk electrolyte concentration $\left(\mathrm{mole} / \mathrm{m}^{3}\right), \mathrm{z}_{\mathrm{i}}$ is the valence of the counterion, $\mathrm{n}$ is the number of the ions in the unit volume $\left(\mathrm{m}^{3}\right)$. Rest of the symbols have their usual meaning or were defined above. Thus calculated values are collected in Table 2 where it can be seen that the liposome surface charge is small and amounts only one unite charge present on $30.2 \mathrm{~nm}^{2}$ if planar electrical double layer is considered, or on $27.0 \mathrm{~nm}^{2}$ of the surface if calculated from spherical model of the double layer. It means that statistically only one of 46 DPPC molecules bears unit electrical charge (or 42 molecules if spherical model is considered). In other words, only $2.15 \%$ (or $2.40 \%$ ) of the liposome surface is charged. This is graphically depicted in Fig. 7. Ikonen et al. (2010) have calculated that in $17 \mathrm{mM}$ of $1: 1$ electrolyte only less than $5 \%$ of the mixed POG/POPC lipid liposomes is charged, despite the fact that $30 \%$ was anionic (POPG) and the role of $\mathrm{Cl}^{-}$anions was probably minor if ever. This support our calculation of the liposome surface charge. Obviously, rest of the liposomes listed in Table 1 possess much lower their surface charge. On the other

Table 2 Calculated surface charge of DPPC liposome in $1 \mathrm{mM} \mathrm{NaCl}$ solution and the percentage of charged surface of liposome at $20{ }^{\circ} \mathrm{C}$

\begin{tabular}{llllllll}
\hline $\begin{array}{l}\text { Model of } \\
\text { e.d.l. }\end{array}$ & $\begin{array}{l}\text { Liposome } \\
\text { diameter } \mathrm{nm}\end{array}$ & $\begin{array}{l}\text { Surface } \\
\text { potential, } \Psi_{\mathrm{o}} \\
\mathrm{mV}\end{array}$ & $\begin{array}{l}\text { Surface charge, } \sigma_{\mathrm{o}} \\
\mathrm{C} / \mathrm{nm}^{2} \times 10^{21}\end{array}$ & $\begin{array}{l}\text { Surface per unit } \\
\text { charge } \mathrm{nm}^{2} / \mathrm{e}_{\mathrm{o}}\end{array}$ & $\begin{array}{l}\text { Number of } \\
e \text { charges/ } \\
\text { liposome }\end{array}$ & $\begin{array}{l}\text { Number of DPPC } \\
\text { molec./1 } e \text { charge }\end{array}$ \\
\hline Planar & 131 & -58.2 & 5.30 & 30.2 & 1781 & 46 & $\begin{array}{l}\% \text { of } \\
\text { charged } \\
\text { surface }\end{array}$ \\
Spherical & 131 & -58.2 & 5.92 & 27.0 & 1992 & 42 & 2.15 \\
\hline
\end{tabular}

Fig. 7 a Ilustration of the amount of DPPC molecules on the liposome surface per one elemental charge: 46 DPPC molecules/unit charge from planar model of the electrical double layer (42 molecules from spherical e.d.l. model).

b Percentage of charged DPPC liposome surface: 2.15 or $2.4 \%$ calculated from planar or spherical electrical double layer model, respectively
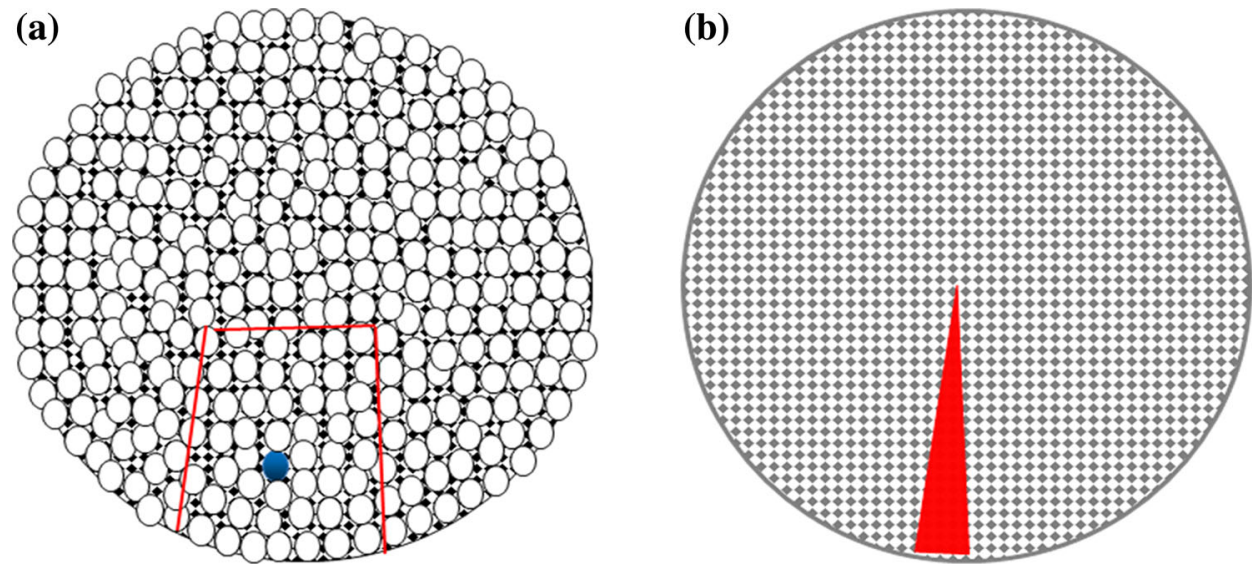
hand, Liu et al. (2001) have found (using optical second harmonic generation technique) for negatively charged unilamellar DOPG liposomes in $\mathrm{NaCl}$ or $\mathrm{MgSO}_{4}$ solutions the surface potential $20-100 \mathrm{mV}$ and the charge density of ca. 1 charge/70 $\AA$, which corresponded to the phospholipid head group size. Our results clearly show that zwitterionic liposomes like DPPC or DOPC do not possess greatly charged surface and the charge probably is due to some preferable orientation of the diopoles of polar phospholipid heads (Makino et al. 1991).

\section{Conclusions}

From the polydispersity index (PDI) changes one may conclude that DPPC and DOPC liposomes dispersed in $1 \mathrm{mM}$ $\mathrm{NaCl}$ solution during $60 \mathrm{~min}$ action of the PLC enzyme, both at 20 and $37^{\circ} \mathrm{C}$, are relatively stable and monodisperse despite the fact that the enzyme amount present in the solution is sufficient to hydrolyze completely the liposomes at $37{ }^{\circ} \mathrm{C}$. In phosphate buffer and PLC presence the DPPC liposomes are unstable which results from efficient hydrolysis reaction. However, this is not the case for DOPC liposomes whose polydispersity index changes are similar to those in $\mathrm{NaCl}$ solution. This indicates that the hydrolysis reaction in this system does not occur simultaneously on all the liposome vesicles present and still after $60 \mathrm{~min}$ some amount of the original liposome vesicles are present.

The obtained results show that zeta potential is not very much sensitive parameter for tracking PLC hydrolysis reaction of DPPC or DOPC liposomes, especially in phosphate buffer. This is because zeta potential the liposomes, it seems, does not depend on their decreasing concentration and size (polydispersity) in the reaction system, if their surface structure (charge) is preserved. Nevertheless the liposome zeta potentials observed during $60 \mathrm{~min}$ of their contact with PLC enzyme depict distinct differences in the DPPC and DOPC liposomes properties and allow conclude that the latter are easier hydrolyzed. The biggest negative zeta potential is found for DPPC liposomes in $1 \mathrm{mM} \mathrm{NaCl}$ solution at 20 and $37{ }^{\circ} \mathrm{C}, 56.7$ and $55.5 \mathrm{mV}$, respectively. The calculated values of the surface potential $\psi_{\mathrm{o}}$ are only a little bigger than the zeta potential $\zeta, 58.2$ and $59.3 \mathrm{mV}$, respectively. The calculated surface charge shows that only 1 unit charge is present on 42-46 DPPC polar heads. In other words, as little as $2-2.5 \%$ of the liposome surface bear the electric charge. Therefore one may consider contribution of the residual charge ('smeared charge') of the zwitterionic heads of phospholipid in the charge/potential creation.

Acknowledgments Support from Marie Curie Initial Training Network "ComplexWetting Phenomena" (Project number 607861) is highly appreciated.
Open Access This article is distributed under the terms of the Creative Commons Attribution 4.0 International License (http://crea tivecommons.org/licenses/by/4.0/), which permits unrestricted use, distribution, and reproduction in any medium, provided you give appropriate credit to the original author(s) and the source, provide a link to the Creative Commons license, and indicate if changes were made.

\section{References}

Akbarzadeh, A., Rezaei-Sadabady, R., Davaran, S., Joo, S.W., Zarghami, N., Hanifehpour, Y., Samei, M., Kouhi, M., NejatiKoshki, K.: Liposome: classification, preparation, and applications. Nanoscale Res. Lett. 8, 1-9 (2013)

Aloulou, A., Rodriguez, J.A., Fernandez, S., van Oosterhout, D., Puccinelli, D., Carriere, F.: Exploring the specific features of interfacial enzymology based on lipase studies. Biochim. Biophys. Acta 1761, 995-1013 (2006)

Bard, A.J., Faulkner, L.R.: Electrochemical Methods; Fundamentals and Applications, 2nd edn., pp. 546-551. Willey, New York (2001)

Bamji-Mirza, M., Yao, Z.: Phospholipases-Lipid Library. http:// lipidlibrary.aocs.org/animbio/phospholipases/index.htm. March 5,2015

Barenholz, Y.: Liposome application: problems and prospects. Curr. Opin. Colloid Interface 6, 66-77 (2001)

Becker, O.M., MacKerell, Jr., A.D., Roux, B, Watanabe, M.: Computional Biochemistry and Pysics, pp. 475-76. Marcel Dekker, New York (2001)

Bergstrand, N.: Liposomes for Drug Delivery from Physico-Chemical Studies to Applications. Acta Univ. Upsaliensis, Uppsala (2003)

Bjorklid, E., Little, C.: Isoelectric point of phospholipase C from Bacillus cereus. FEBS Lett. 113, 161-163 (1980)

Bunney, T.D., Katan, M.: PLC regulation: emerging pictures for molecular mechanisms. Trends Biochem. Sci. 36, 88-96 (2011)

Burack, W.R., Biltonen, R.L.: Lipid bilayer heterogeneities and modulation of phospholipase A2 activity. Chem. Phys. Lipids 73, 209-222 (1994)

Clarke, R.J.: The dipole potential of phospholipid membranes and methods for its detection. Adv. Colloid Interface Sci. 89-90, 263-281 (2001)

del C. Luzardo, M., Peltzer, G., Disalvo, E.A.: Surface potential of lipid interfaces formed by mixtures of phosphatidylcholine of different chain lengths. Langmuir 14, 5858-5863 (1998)

Dual, J.S., Rana, A.C., Bhandari, A.K.: Liposome: methods of preparation and applications. Int. J. Pharm. Stud. Res. 3, 14-20 (2012)

Fisher, A.B., Mehendra, J.: Phospholipases: Degradation of Phospholipids in Membranes and Emulsions. In: eLS. Wiley, Chichester (2009), http://www.els.net [doi: 10.1002/ 9780470015902.a0001394.pub2]

Gross, E., Bedlack, E.S., Loew, L.M.: Dual-wavelength ratiometric fluorescence measurement of the membrane dipole potential. Biophys. J. 67, 208-216 (1994)

Gudmand, M., Rocha, S., Hatzakis, N.S., Peneva, K., Müllen, K., Stamou, D., Uji-I, H., Hofkens, J., Bjørnholm, T., Heimburg, T.: Influence of lipid heterogeneity and phase behavior on phospholipase $\mathrm{A}_{2}$ action at the single molecule level. Biophys. J. 98, 1873-1882 (2010)

Haldky, S.B., Haydon, D.A.: Membrane conductance and dipole potential. Biochim. Biophys. Acta 318, 429 (1973)

Hasanovic, A., Holick, C., Fishinger, K., Valenta, C.: Improvement in physicochemical parameters of DPPC liposomes and increase in 
skin permeation of acyclovir and minoxidil by the addition of cationic polymers. Eur. J. Pharm. Biopharm. 75, 148-153 (2010)

Hunter, R.J.: Zeta Potential in Colloid Science. Academic Press, London (1981)

Ikonen, M., Murtomäki, L., Kontturi, K.: Microcalorimetric and zeta potential study on binding of drugs on liposomes. Colloids Surf. B: Biointerfaces 78, 275-282 (2010)

Jones, M.N.: The surface properties of phospholipid liposome systems and their characterization. Adv. Colloid Interface 54, 93-128 (1995)

Lewis, R.N.A.H., Sykes, B.D., McElhaney, R.N.: Thermotropic phase behavior of model membranes composed of phosphatidylcholines containing cis-monounsaturated acyl chain homologues of oleic acid. Differencial scanning calorimetric and 31P-NMR spectroscopic studies. Biochemistry 27, 880-887 (1988)

Liu, Y., Yan, E.C.Y., Zhao, X., Eisenthal, K.B.: Surface potential of charged liposomes determined by second harmonic generation. Langmuir 17, 2063-2066 (2001)

Lyklema, J.: Molecular interpretation of electrokinetic potentials. Curr. Opin. Colloid Interface Sci. 15, 125-130 (2010)

Lyklema, J.: Surface charges and electrokinetic charges: distinctions and juxtapositionings. Colloid Surf. A: Physicochem. Eng. Aspects 376, 2-8 (2011)

Makino, K., Yamada, T., Kimura, M., Oka, T., Oshima, H.: Temperature- and ionic strength-induced conformational changes in the lipid head group region of liposomes as suggested by zeta potential data. Biophys. Chem. 41, 175-183 (1991)

Maharani, B., Arab-tehrany, E., Kheirolomoom, A., Reshetov, V., Stebe, M.J., Linder, M.: Optimization and characterization of liposome formulation by mixture design. Analyst 137, 773-786 (2012)

Meland, H.G., Røv-Johnsen, A., Smistad, G., Hiorth, M.: Studies on surface coating of phospholipid vesicles with a non-ionic polymer. Colloids Surf B: Biointerfaces 114, 45-52 (2014)

Milhaud, J.: New insights into water-phospholipid model membrane interactions. Biochim. Biophys. Acta 1663, 19-51 (2004)

Mo, S.J., Kim, J., Cho, K.W.: Enzymatic properties of an extracellural phospholipase $\mathrm{C}$ purified from a marine streptomycete. Biosci. Biotechnol. Biochem. 73, 2136-2137 (2009)

Mouritsen, O.G., Andresen, T.L., Halperin, A., Hansen, P.L., Jakobsen, A.F., Jensen, U.B., Jensen, M.Ø., Jørgensen, K., Kaasgaard, T., Leidy, C., Simonsen, A.C., Peters, G.H., Weiss, M.: Activation of interfacial enzymes at membrane surfaces. J. Phys.: Condens. Matter 18, 1293-1304 (2006)

Muddana, H.S., Gullapalli, R.R., Manias, E., Butler, P.J.: Atomistic simulation of lipid and DiL dynamics in membrane bilayers under tension. Phys. Chem. Chem. Phys. 13, 1368-1378 (2011)

O'Brien, R., White, L.R.: Electrophoretic mobility of a spherical colloidal particle. J. Chem. Soc., Faraday Trans. 2(74), $1607-1626$ (1978)

Ohvo-Rekilä, H., Ramstedt, B., Leppimäki, P., Slotte, J.P.: Cholesterol interactions with phospholipids in membranes. Prog. Lipid Res. 41, 66-97 (2002)

Oshima, H., Furosawa, K.: Electrical Penomena at Interfaces: Fundamentals, Measurements and Applications, Ch. 1, p. 9. Marcel Dekker, New York (1998)

Patil, Y.P., Jadhav, S.: Novel methods for lipsome preparation. Chem. Phys. Lipids 177, 8-18 (2014)

Patra, M., Kartunen, M., Hyvonen, M.T., Falck, E., Lindqvist, P., Vattulainen, I.: Molecular dynamic simulation of lipid bilayers: major artifacts due to truncating electrostatic interactions. Biophys. J. 84, 3636-3645 (2003)
Raffo Iraolagoitia, X.L., Florencia Martini, M.: $\mathrm{Ca}^{2+}$ adsorption to lipid membranes and the effect of cholesterol in their composition. Colloids Surf. B: Biointerfaces 76, 215-220 (2010)

Róg, T., Pasenkiewicz-Gierula, M., Vattulainen, I., Karttunen, M.: Ordering effects of cholesterol and its analogues. Biochim. Biophys. Acta 1788, 97-121 (2009)

Salgin, S., Salgin, U., Bahadir, S.: Zeta potentials and Isoelectric points of biomolecules: the effects of ion types and ionic strength. Int. J. Electrochem. Sci. 7, 12404-12414 (2012)

Satoh, K.: Determination of binding constant of $\mathrm{Ca}^{2+}, \mathrm{Na}^{+}$, and $\mathrm{Cl}^{-}$ ions to liposomal membranes of dipalmitoylphosphaticholine at gel phase by particle electrophoresis. Biochim. Biophys. Acta 1239, 239-248 (1995)

Takeuchi, K., Ishihara, M., Kawaura, C., Noji, M., Furuno, T., Nakanishi, M.: Effect of zeta potential of cationic liposomes containing cationic cholesterol derivatives on gene transfection. FEBS Lett. 397, 207-209 (1996)

Vaccaro, A.M., Tatti, M., Ciaffoni, F., Salvioli, R., Barca, A., Scerch, C.: Effect of saposins A and C on the enzymatic hydrolysis of liposomal glucosylceramide. J. Biol. Chem. 272, 16862-16867 (1997)

Vaknin, D., Kjaer, K., Als-Nielsen, J., Loschet, M.: Structural properties of phosphatidylcholine in a monolayer at the air/water interface. Neutron reflection study and reexamination of X-ray reflection measurements. Biophys. J. Biophys. Soc. 59, 1325-1332 (1991)

Wagner, K., Brezesinski, G.: Phospholipases to recognize model membrane structures on a molecular length scale. Curr. Opin. Colloid Interface 13, 47-53 (2008)

Wang, L.: Measurements and implications of the membrane dipole potential. Annu. Rev. Biochem. 81, 615-635 (2012). www. annualreviews.org

Warshawiak, D.T., Muellner, M.J., Chachisvilis, M.: Effect of membrane tension on the electric field and dipole potential of lipid bilayer membrane. Biochem. Biophys. Acta 1808, 2608-2617 (2011). Worthington Enzyme Manual, http://www. worthingtonbiochem.com:8080/enzyme_manual/PLC/

Wu, H.L., Yu, L., Tong, Y., Ge, A., Yau, S., Osawa, M., Ye, S.: Enzyme-catalyzed hydrolysis of the supported phospholipid bilayers studied by atomic force microscopy. Biochim. Biophys. Acta 1828, 642-651 (2013)

Yamauchi, K., Hayashi, M., Yamamoto, I.: Dotriacontanedioyl-snglycero-3-phosphocholine: a cyclic lipid used for phospholipase A2-catalyzed modulation of the liposome surface charge. J. Biochem. 125, 853-857 (1999)

Yamauchi, K., Yamamato, I., Kinoshita, M.: Surface charge modulation of liposomes by enzymatic hydrolysis of macrocyclic 1,2dotriacontanedioyl-sn-glycero-3-phosphocholine. Biochim. Biophys. Acta 938, 51-60 (1988)

Zaru, M., Manca, M.Z., Fadda, A.M., Antimisiaris, A.G.: Chitosancoated liposomes for delivery to lungs by nebulization. Colloids Surf. B: Biointerfaces 71, 88-95 (2009)

Zuidam, N.J., Crommelin, D.J.A.: Chemical hydrolysis of phospholipids. J. Pharm. Sci. 84, 1113-1119 (1995)

Zuidam, N.J., Gouw, H.K.M.E., Barenholz, Y., Crommelin, D.J.A.: Physical (in)stability of liposomes upon chemical hydrolysis: the role of lysophospholipids and fatty acids. Biochim. Biophys. Acta 1240, 101-110 (1995) 